\title{
ANÁLISIS COMPARATIVO DEL CAMBIO ORGANIZACIONAL E INSTITUCIONAL DE DOS INCUBADORAS DE EMPRESAS*
}

\author{
Geovanny Perdomo Charry** \\ José Enrique Arias Pérez ${ }^{* *}$ \\ Nelson Enrique Lozada ${ }^{* * *}$
}

Recibido: 01 de octubre de 2015 Aprobado: 19 de marzo de 2016

\section{RESUMEN}

El objetivo de este artículo es realizar un análisis comparado del cambio organizacional e institucional de dos incubadoras de empresas, una situada en Medellín, Colombia y la otra en Barcelona, España; se consideran la influencia de factores internos y externos, y la existencia, incorporación e institucionalización de políticas públicas y programas de desarrollo empresarial e innovación. En lo metodológico, se utilizó la estrategia cualitativa del estudio de caso, soportado en el análisis documental y la entrevista semiestructurada. Los principales resultados muestran que la incubadora colombiana cambió su objeto social y razón de ser por necesidad de auto-sostenibilidad financiera y por la falta de coordinación y articulación con las organizaciones del Sistema Nacional de Ciencia, Tecnología e Innovación; y la española consolidó su objeto social y amplió las capacidades organizacionales por las oportunidades que le brindó el entorno favorable del Sistema Nacional de Ciencia, Tecnología e Innovación.

\section{PALABRAS CLAVE}

Incubadora de empresas, emprendimiento empresarial, cambio organizacional, cambio institucional, gobernanza.

\section{CLASIFICACIÓN JEL}

M13, L26, M38

\section{CONTENIDO}

Introducción; 1. Cambio organizacional y gobernanza, 2. Metodología de investigación; 3. Resultados; 4. Conclusiones; Bibliografía, Anexos

\footnotetext{
Este artículo de investigación es producto de la pasantía doctoral del profesor Geovanny Perdomo, en el Doctorado en Economía de la Empresa de la Universidad Autónoma de Barcelona, España, Pasantía Investigativa en Barcelona Activa y la Universidad Autónoma de Barcelona. Financiación de la Universidad Eafit y el Programa Enlazamundos de la Agencia Sapiencia de Medellín. Pasantía desde el 1 de marzo al 31 de octubre de 2011.

" Administrador de empresas, Universidad Cooperativa de Colombia, Neiva, Colombia. Especialista en Derecho Comercial y Financiero, Universidad Católica de Colombia, Bogotá, Colombia. Magíster en Gerencia de Recursos Humanos, Universidad de Manizales, Manizales, Colombia. Doctor en Administración de EAFIT, Medellín, Colombia; Decano de la Facultad de Ciencias Económicas, Universidad San Buenaventura, Cali. Dirección postal: Avenida 10 de Mayo, La Umbría, Vía a Pance, Edificio el Cedero, oficina 3-301, Cali, Colombia. Tel 57 (2) 4882222 Extensión 311. Correo electrónico: gperdomo@usbcali.edu.co.

".. Administrador de empresas, Fundación Universitaria Luis Amigó, Medellín, Colombia. Especialista en Gerencia de Sistemas y Tecnología, Universidad Pontificia Bolivariana, Medellín, Colombia. Magíster en Gestión de CTI, Universidad de Antioquia, Medellín, Colombia. Doctorando en Dirección de Empresas, Universidad de Valencia, España. Profesor Departamento de Ciencias Administrativas, Universidad de Antioquia; miembro del Grupo de Investigación en Gestión Organizacional-GESTOR. Dirección postal: Calle 70 N. 52-21 oficina 13-105, Medellín, Colombia. Tel. 57 (4) 2195846. Correo electrónico: jenrique.arias@udea.edu.co.

"..** Administrador de empresas, Corporación Universitaria Adventista. Especialista en Gerencia de las Organizaciones, Corporación Universitaria Adventista. Magíster en Administración, Universidad de Montemorelos, Montemorelos, México. Doctorando en Dirección de Empresas Universidad de Valencia, España. Profesor Departamento de Ciencias Administrativas y miembro del Grupo de Investigación en Gestión Organizacional-GESTOR, Universidad de Antioquia, Medellín, Colombia. Dirección postal: Calle 70 N. ${ }^{\circ}$ 52-21 oficina 13-414, Medellín, Colombia. Tel. 57 (4) 2198833. Correo electrónico: nelson.lozada@udea.edu.co.
} 


\title{
A COMPARATIVE ANALYSIS FOR THE BUSINESS INCUBATORS INSTITUTIONAL AND ORGANIZATIONAL CHANGE ABSTRACT
}

The objective of this article is to compare organizational and institutional change in two business incubators, one in Medellin, Colombia and another one in Barcelona, Spain; The influence of internal and external factors are both considered as well as the existence, incorporation and institutionalization of public policies as well as business and entrepreneurial programs. A qualitative case study strategy was used for developing the methodological aspect, which supported the documental analysis for the semistructured interview. The main results show that the Colombian incubator changed its business name because of financial self sustainability needs and lack of coordination and articulation from the National Science, Technology and Innovation System, while the incubator from Spain consolidated its business name broadening its organizational capacities thanks to the favorable opportunities offered by National Science, Technology and Innovation system.

\section{KEY WORDS}

Business incubator, entrepreneurship, organizational change, institutional change, governance.

\section{JEL CLASSIFICATION}

M13, L26, M38

\section{CONTENT}

Introduction; 1. Governance and Organizational Change, 2. Research Methodology; 3. Results; 4. Conclusions; Bibliography, Attachments.

\section{ANÁLISE COMPARATIVO DA MUDANÇA ORGANIZACIONAL E INSTITUCIONAL DE DUAS INCUBADORAS DE EMPRESAS}

\section{RESUMO}

O objetivo deste artigo é realizar uma análise comparado da mudança organizacional e institucional de duas incubadoras de empresas, uma situada em Medellín, Colômbia e a outra em Barcelona, Espanha; se consideram a influência de fatores internos e externos, e a existência, incorporação e institucionalização de políticas públicas e programas de desenvolvimento empresarial e inovação. No metodológico, se utilizou a estratégia qualitativa do estudo de caso, suportado na análise documental e a entrevista semiestruturada. Os principais resultados mostram que a incubadora colombiana mudou seu objeto social e razão de ser por necessidade de auto-sustentabilidade financeira e pela falta de coordenação e articulação com as organizações do Sistema Nacional de Ciência, Tecnologia e Inovação; e a espanhola consolidou seu objeto social e ampliou as capacidades organizacionais pelas oportunidades que the brindou o entorno favorável do Sistema Nacional de Ciência, Tecnologia e Inovação.

\section{PALAVRAS CHAVES}

Incubadora de empresas, empreendimento, mudança organizacional, mudança institucional, governança.

\section{CLASSIFICAÇÃO JEL}

\author{
M13, L26, M38
}

\section{CONTEÚDO}

Introdução; 1. Mudança organizacional e governança, 2. Metodologia de investigação; 3. Resultados; 4. Conclusões; Bibliografia, Anexos. 


\section{INTRODUCCIÓN}

El informe anual del GEM (2012; 2015) para España y Colombia, respectivamente, indica que Barcelona y Medellín ocupaban un lugar protagónico en el desarrollo del emprendimiento y la innovación; Medellín, como la primera ciudad en la promoción de la política pública orientada a la innovación y el emprendimiento, y Barcelona, como la primera ciudad española en desarrollo empresarial e innovador; se resalta de esta manera, como uno de los actores fundamentales en la construcción e implementación de la política pública, el papel fundamental que las incubadoras de empresas desempeñan.

Dada la importancia de las incubadoras, Anderson y Al-Mubaraki (2012), al igual que Cooper, Hamel y Connaughton (2012), sugieren que ha habido un creciente interés por identificar los distintos factores de éxito; sin embargo, la gran mayoría de estudios se han realizado en el contexto de países desarrollados en los que predominan sectores de alta tecnología; por ende, es notoria la ausencia de trabajos que pongan en evidencia la evolución y el camino transitado por las incubadoras que han surgido en economías que no son intensivas en conocimiento.

La española fue concebida como una incubadora municipal que propiciaba el nacimiento de nuevas empresas, pero su evolución la convirtió en una agencia de desarrollo local exitosa según la OECD (2009), inserta en varios parques tecnológicos que ha promovido. Además, como lo afirma el GEM (2012), los principales aportes han significado el incremento en el número de empresas creadas (624 empresas incubadas en 25 años de operación) y en la tasa de actividad emprendedora (TAE) en los últimos años. Por su parte, la colombiana pasó de ser una incubadora de base tecnológica a convertirse en un centro integral de servicios empresariales que trabaja en red y que ha cambiado cuatro veces su modelo de incubación y lo ha transferido en 15 oportunidades en el país y ocho en el contexto internacional, razón por la cual ha incrementado el relacionamiento, la creación de empresas y el fortalecimiento empresarial en el contexto nacional, a través de su interacción con otros actores del sistema como universidades, cámaras de comercio, centros de investigación, parques tecnológicos, etc.

Este artículo tiene el propósito comparar el cambio organizacional entre la incubadora de empresas de la ciudad de Medellín (Colombia) y la de Barcelona (España) de cómo han influido los factores exógenos y endógenos y la implicación de las políticas de desarrollo empresarial o transformación productiva; para esto, en el primer apartado del artículo se trata el tema del cambio organizacional y la gobernanza, luego se plantea el diseño metodológico, a continuación se presentan los resultados, y por último se plantean las conclusiones. 


\section{CAMBIO ORGANIZACIONAL Y GOBERNANZA}

El estudio del emprendimiento y, como lo sugieren Hackett y Dilts (2004a, 2004b), de forma concreta, las incubadoras han sido abordados desde distintas perspectivas, entre ellas, las dos más importantes son el cambio organizacional y la gobernanza.

Según Meyer y Scott (1992), Scott (1995) y Battilana y Casciaro (2012), el cambio organizacional tiene que ver con la modificación y adaptación de las rutinas organizacionales a las contingencias del contexto interno, en el cual son claves los agentes de cambio, las redes y los procesos de institucionalización. Para Meny y Thoening (1992), Peters (2004), Muller (2006) y Vargas y De la Rosa (2011) la otra perspectiva, la gobernanza, tiene que ver con la formulación y legitimación de la toma de decisiones del sector público y privado relacionadas con la innovación y el desarrollo empresarial donde, como lo manifiesta Monnier (1992), han surgido diversas denominaciones para referirse a este mismo asunto, entre ellas la nueva gestión pública.

Ahora, es recurrente encontrar en la literatura dos niveles de análisis tal como lo afirman Hansen y otros (2000), Hackett y Dilts (2004a, 2004b), Peña (2004), Scillitoe y Chakrabarti (2010), Tsai y otros (2009): un nivel macro, donde el objeto de estudio es la incubadora en su conjunto y, de manera específica, su relación con el incubado, la red y la comunidad; además, un segundo nivel, donde el objeto de estudio se centra en entender la existencia, desarrollo y evolución en un contexto sectorial, local, regional, nacional e internacional de la incubadora.

Lo anterior permite identificar la influencia de factores internos y externos, y la existencia, incorporación e institucionalización de políticas públicas y programas de desarrollo empresarial e innovación en cuatro niveles: el individual, que alude al incubado; el organizacional, asociado a la incubadora; el meso, relacionado con la red, y el macro, referido a la comunidad.

\section{METODOLOGÍA DE INVESTIGACIÓN}

La aplicación de la metodología cualitativa de casos en esta investigación se lleva a cabo bajo el diseño general del estudio de caso múltiple que sugiere Yin (2003), cuya estructura complementaria se sintetiza en el gráfico 1. 
Gráfico 1. Proceso completo del estudio de caso múltiple

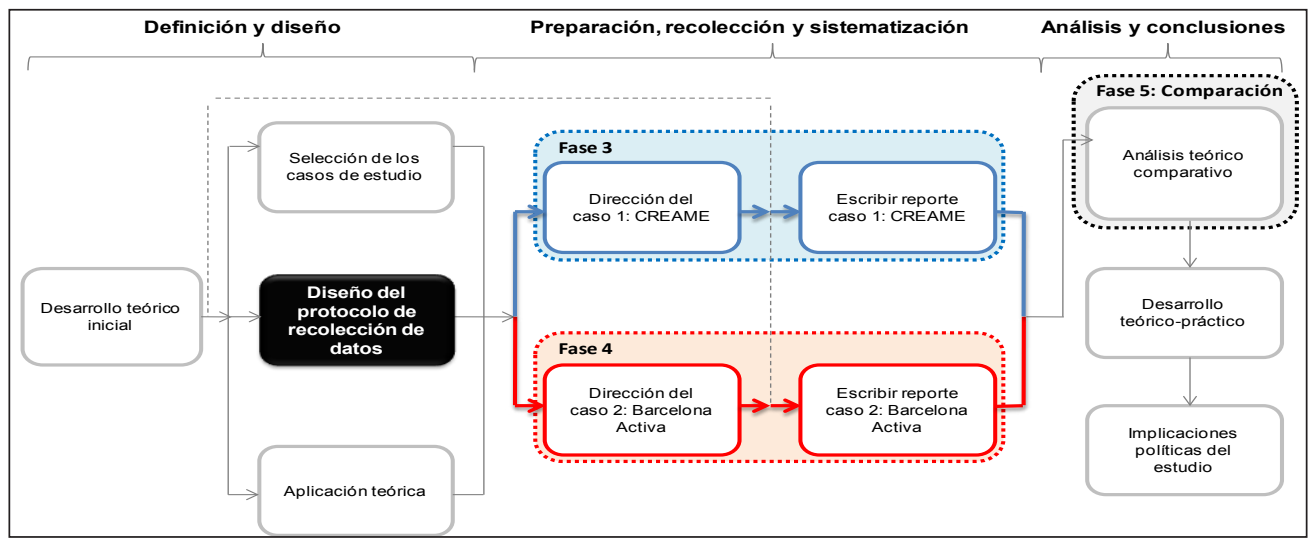

Fuente: elaboración propia

Como ya se mencionó, la construcción de los casos sigue la metodología planteada por Yin (2003) y Eisenhardt (1989), debido a que esta no reside en una generalización estadística, a partir de un grupo de sujetos hasta un universo, sino que se trata de una generalización analítica que utiliza el estudio de caso múltiple para ilustrar, representar o generalizar un marco teórico.

Las dos incubadoras analizadas fueron Barcelona Activa, en España, y Créame, en Colombia; para la recolección de la información, se utilizó la entrevista semiestructurada a veinticinco personas (25) en cada organización objeto de estudio, que incluye directivos (3), empleados (10), representantes de entidades (2), incubados (10)'. Los cinco criterios de selección de las personas consultadas fueron: conocimiento, experiencia, antigüedad en el proceso, reconocimiento en el medio y liderazgo organizacional o institucional.

Para el análisis de la información cualitativa también se consideraron unos criterios de selección de las variables estudiadas que partían principalmente de la revisión sistemática de literatura, referida a las perspectivas teóricas estudiadas para explicar el cambio (factores internos y externos, políticas y programas, cambio institucional, cambio organizacional e institucionalización); estas perspectivas fueron identificadas, en primera instancia en la literatura, como escalas de medidas con conceptos de segundo orden que luego, se complementaron con el análisis cualitativo al emerger nuevas categorías de análisis.

1 En los anexos se puede consultar las preguntas que se realizaron a cada uno de los entrevistados. 
Para categorizar, se hizo una codificación con el apoyo de un programa de análisis cualitativo $^{21}$, que permitió identificar citas o fragmentos de texto con similitudes, recurrencias y vínculos comunes que fueron agrupados por las categorías centrales del estudio. Por último, se triangularon los resultados, discutiéndolos con los sujetos de investigación, y con la consulta de documentos de las dos organizaciones.

\section{RESULTADOS}

La explicación de las similitudes y diferencias encontradas en los procesos de cambio organizacional e institucional en ambas incubadoras se describe en los siguientes apartados; se sigue la ruta derivada del enfoque teórico construido; primero la influencia de los factores interno y externo; posteriormente, la descripción de la evolución de las políticas y programas en materia de desarrollo empresarial e innovación; luego, la incorporación de dichas políticas y programas como motor de la evolución y desarrollo de las incubadoras, y al final, la explicación de cómo las institucionalizaron cada una de estas organizaciones.

\subsection{Influencia de los factores internos y externos en el cambio de las organizaciones}

Al estudiar el fenómeno del cambio organizacional, se descubre y confirma que, en las dos incubadoras, como lo señalan Crozier y Friedberg (1990), la política y la cultura inciden en el cambio de los actores, y estos, a su vez en la transformación de los sistemas y resultados de las organizaciones. En ambos casos, la política está expresada en las decisiones de la Administración Pública adelantadas en materia de desarrollo empresarial e innovación, en cada contexto y en tiempos diferentes; en el caso de España, por el gobierno local de Barcelona, y en Colombia, por las políticas y programas nacionales y locales que detonan cambios culturales en el desarrollo de los emprendedores, empresarios y empresas, como se observa en la tabla 1.

$2 \quad$ El software utilizado para la codificación y el análisis de la información fue el Atlas Ti versión 7. 
Tabla 1. Análisis comparativo por niveles de análisis y categorías selectivas de los factores internos y externos

\begin{tabular}{|c|c|c|c|c|c|}
\hline & & $\begin{array}{l}\text { Incubadora } \\
\text { colombiana }\end{array}$ & & $\begin{array}{l}\text { Incubadora } \\
\text { española }\end{array}$ & \\
\hline Niveles & Factores & Categorías & $\begin{array}{l}\text { Compara- } \\
\text { tivo }\end{array}$ & Categorías & Análisis descriptivo \\
\hline \multirow{3}{*}{$\begin{array}{l}\text { Individuo: } \\
\text { incubado }\end{array}$} & Externos & $\begin{array}{l}\text { Organización en } \\
\text { red }\end{array}$ & - & $\begin{array}{l}\text { Entorno } \\
\text { innovador }\end{array}$ & $\begin{array}{l}\text { La diferencia principal que encuentran } \\
\text { los emprendedores incubados está } \\
\text { en el mayor nivel de madurez que ha } \\
\text { alcanzado la ciudad de Barcelona y su } \\
\text { incubadora, respecto al nuevo concepto } \\
\text { de incubación, es decir, transitar de una } \\
\text { modelo de incubación en reda un entorno } \\
\text { innovador. }\end{array}$ \\
\hline & \multirow[b]{2}{*}{ Internos } & $\begin{array}{l}\text { Perfil del } \\
\text { emprendedor }\end{array}$ & - & $\begin{array}{l}\text { Perfil del } \\
\text { emprendedor }\end{array}$ & $\begin{array}{l}\text { El perfil del emprendedor en Barcelona } \\
\text { se diferencia en dos características clave: } \\
\text { hablar más de dos idiomas y tener mayor } \\
\text { experiencia empresarial. }\end{array}$ \\
\hline & & $\begin{array}{l}\text { Perfil de la empresa } \\
\text { incubada }\end{array}$ & - & $\begin{array}{l}\text { Perfil de la } \\
\text { empresa } \\
\text { incubada }\end{array}$ & $\begin{array}{l}\text { Las empresas incubadas en Medellín } \\
\text { son principalmente Empresas de Base } \\
\text { Tecnológica (EBT) y de valor agregado, } \\
\text { mientras en Barcelona, son EBT, empresas } \\
\text { creativas, de valor agregado y con conte- } \\
\text { nido innovador. }\end{array}$ \\
\hline \multirow{4}{*}{$\begin{array}{l}\text { Micro: orga- } \\
\text { nización }\end{array}$} & & $\begin{array}{l}\text { Respuestas al } \\
\text { cambio }\end{array}$ & 0 & $\begin{array}{l}\text { Respuestas al } \\
\text { cambio }\end{array}$ & $\begin{array}{l}\text { Coinciden en los tipos de respuestas: } \\
\text { adaptación, transformación, innovación } \\
\text { y resistencia, pero con propósitos muy } \\
\text { distintos, la incubadora colombiana por } \\
\text { necesidad de auto-sostenibilidad y la } \\
\text { española por oportunidad. }\end{array}$ \\
\hline & Externos & $\begin{array}{l}\text { Diseño y operación } \\
\text { de políticas y } \\
\text { programas }\end{array}$ & - & \begin{tabular}{l|} 
Diseño y \\
operación de \\
políticas y \\
programas
\end{tabular} & $\begin{array}{l}\text { También concuerdan con la participación } \\
\text { y colaboración en el diseño y operación de } \\
\text { políticas y programas de emprendimiento } \\
\text { e innovación, sin embargo, la incubadora } \\
\text { en Medellín las ayuda a diseñar, pero no } \\
\text { siempre las ejecuta; mientras que la espa- } \\
\text { ñola, las diseña y ella misma las ejecuta, } \\
\text { por estar apoyada en lo financiero por el } \\
\text { Ayuntamiento, es decir, es un brazo de } \\
\text { acción pública pero con características } \\
\text { privadas. }\end{array}$ \\
\hline & \multirow[b]{2}{*}{ Internos } & $\begin{array}{l}\text { Perfil de la } \\
\text { organización }\end{array}$ & - & $\begin{array}{l}\text { Perfil de la } \\
\text { organización }\end{array}$ & $\begin{array}{l}\text { En su inicio fueron organizaciones muy } \\
\text { similares, pero a través del tiempo y por } \\
\text { circunstancias el entorno, una se desvió } \\
\text { de su objeto social (la colombiana) y la } \\
\text { otra lo fortaleció: incubar empresas. }\end{array}$ \\
\hline & & $\begin{array}{l}\text { Trayectoria de la } \\
\text { organización }\end{array}$ & 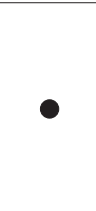 & $\begin{array}{l}\text { Trayectoria } \\
\text { de la organi- } \\
\text { zación }\end{array}$ & $\begin{array}{l}\text { Existe una diferencia marcada en la } \\
\text { trayectoria, porque una se diversificó y } \\
\text { generalizó los recursos, servicios y activi- } \\
\text { dades (la colombiana), la otra, se focalizó } \\
\text { y especializó los recursos, servicios y } \\
\text { actividades. }\end{array}$ \\
\hline
\end{tabular}




\begin{tabular}{|c|c|c|c|c|c|}
\hline & & $\begin{array}{l}\text { Incubadora } \\
\text { colombiana }\end{array}$ & & $\begin{array}{l}\text { Incubadora } \\
\text { española }\end{array}$ & \\
\hline Niveles & Factores & Categorías & $\begin{array}{l}\text { Compara- } \\
\text { tivo }\end{array}$ & Categorías & Análisis descriptivo \\
\hline \multirow{3}{*}{$\begin{array}{l}\text { Micro: orga- } \\
\text { nización }\end{array}$} & \multirow{3}{*}{ Internos } & $\begin{array}{l}\text { Proceso de } \\
\text { incubación }\end{array}$ & $\bullet$ & $\begin{array}{l}\text { Proceso de } \\
\text { incubación }\end{array}$ & $\begin{array}{l}\text { Existe una diferencia clave, mientras la } \\
\text { colombiana no ha podido implementar } \\
\text { un modelo de incubación valido para su } \\
\text { contexto de actuación (cinco versiones } \\
\text { con focos diversos), la otra ha consolida- } \\
\text { do un modelo mixto innovador. }\end{array}$ \\
\hline & & $\begin{array}{l}\text { Recursos y } \\
\text { servicios }\end{array}$ & $\bullet$ & $\begin{array}{l}\text { Recursos y } \\
\text { servicios }\end{array}$ & $\begin{array}{l}\text { Existen limitaciones en todos los tipos de } \\
\text { recursos y servicios en la colombiana por } \\
\text { la falta de apoyo financiero directo, cosa } \\
\text { distinta ocurre con la española que cuenta } \\
\text { con una red de equipamientos especiali- } \\
\text { zados y con excelentes recursos (centro } \\
\text { de iniciativa emprendedora, incubadora, } \\
\text { parques tecnológicos, etc.). }\end{array}$ \\
\hline & & $\begin{array}{l}\text { Capacidades } \\
\text { organizacionales }\end{array}$ & O & $\begin{array}{l}\text { Capacidades } \\
\text { organizacio- } \\
\text { nales }\end{array}$ & $\begin{array}{l}\text { La colombiana no ha generado capacida- } \\
\text { des debido al cambio permanente de su } \\
\text { modelo de incubación, mientras que la } \\
\text { otra sí logró generar capacidades. }\end{array}$ \\
\hline \multirow{6}{*}{ Meso: Red } & \multirow{5}{*}{$\begin{array}{l}\text { Exter- } \\
\text { nos }\end{array}$} & Educación & \multirow{2}{*}{0} & Educación & $\begin{array}{l}\text { Altos niveles de educación en las dos } \\
\text { regiones }\end{array}$ \\
\hline & & Comunicación & & $\begin{array}{l}\text { Comunica- } \\
\text { ción }\end{array}$ & $\begin{array}{l}\text { Altos niveles de comunicación en las } \\
\text { dos ciudades }\end{array}$ \\
\hline & & $\begin{array}{l}\text { Cultura empresa- } \\
\text { rial }\end{array}$ & \multirow{2}{*}{0} & $\begin{array}{l}\text { Habilidades } \\
\text { emprende- } \\
\text { doras }\end{array}$ & $\begin{array}{l}\text { Incremento sustantivo de la cultura } \\
\text { emprendedora }\end{array}$ \\
\hline & & $\begin{array}{l}\text { Mecanismos fi- } \\
\text { nanciación }\end{array}$ & & $\begin{array}{l}\text { Apoyo } \\
\text { financiero } \\
\text { permanente }\end{array}$ & $\begin{array}{l}\text { Incremento importante de mecanismos } \\
\text { de financiación }\end{array}$ \\
\hline & & $\begin{array}{l}\text { Obstáculos x crear } \\
\text { empresa }\end{array}$ & O & $\begin{array}{l}\text { Obstáculos } \\
\text { x crear } \\
\text { empresa }\end{array}$ & $\begin{array}{l}\text { Limitaciones y obstáculos para crear } \\
\text { empresa son iguales }\end{array}$ \\
\hline & Internos & Tipos de redes & $\bullet$ & $\begin{array}{l}\text { Tipos de } \\
\text { redes }\end{array}$ & $\begin{array}{l}\text { El nivel de madurez es distinto. La colom- } \\
\text { biana creó dos tipos de redes: una orga- } \\
\text { nización en red y una de financiación. La } \\
\text { española es una red de redes -entorno } \\
\text { innovador-, que incluye una red de lega- } \\
\text { lización, consultores, financiación, etc. }\end{array}$ \\
\hline \multirow{2}{*}{$\begin{array}{l}\text { Macro: co- } \\
\text { munidad }\end{array}$} & \multirow{2}{*}{$\begin{array}{l}\text { Exter- } \\
\text { nos }\end{array}$} & $\begin{array}{l}\text { Intervención } \\
\text { internacional }\end{array}$ & O & $\begin{array}{l}\text { Intervención } \\
\text { internacio- } \\
\text { nal }\end{array}$ & $\begin{array}{l}\text { Organismos de intervención existen en } \\
\text { las dos regiones. }\end{array}$ \\
\hline & & $\begin{array}{l}\text { Políticas de regu- } \\
\text { lación internacio- } \\
\text { nal }\end{array}$ & ( & $\begin{array}{l}\text { Políticas de } \\
\text { regulación } \\
\text { internacio- } \\
\text { nal }\end{array}$ & $\begin{array}{l}\text { La española incursiona en la formaliza- } \\
\text { ción de políticas de regulación de la CTEI. } \\
\text { en Europa, existe un marco general para } \\
\text { la CTEI en la Unión Europea. }\end{array}$ \\
\hline
\end{tabular}


Análisis comparativo del cambio organizacional e institucional de dos incubadoras de empresas

\begin{tabular}{|c|c|c|c|c|c|}
\hline & \multirow{2}{*}{\multicolumn{2}{|c|}{$\begin{array}{l}\text { Incubadora } \\
\text { colombiana }\end{array}$}} & \multirow{2}{*}{\multicolumn{2}{|c|}{$\begin{array}{l}\text { Incubadora } \\
\text { española }\end{array}$}} \\
\hline & & & & & \\
\hline Niveles & Factores & Categorías & $\begin{array}{l}\text { Compara- } \\
\text { tivo }\end{array}$ & Categorías & Análisis descriptivo \\
\hline \multirow{10}{*}{$\begin{array}{l}\text { Macro: } \mathrm{co-} \\
\text { munidad }\end{array}$} & \multirow[t]{2}{*}{$\begin{array}{l}\text { Exter - } \\
\text { nos }\end{array}$} & $\begin{array}{l}\text { Infraestructura } \\
\text { de conocimiento } \\
\text { internacional }\end{array}$ & $\bigcirc$ & $\begin{array}{l}\text { Infraestruc- } \\
\text { tura de co- } \\
\text { nocimiento } \\
\text { internacio- } \\
\text { nal }\end{array}$ & $\begin{array}{l}\text { Las dos regiones y ciudades cuentan con } \\
\text { muy buena infraestructura de conoci- } \\
\text { miento internacional. }\end{array}$ \\
\hline & & $\begin{array}{l}\text { Apoyo } \\
\text { internacional }\end{array}$ & \multirow{2}{*}{0} & $\begin{array}{l}\text { Apoyo in- } \\
\text { ternacional }\end{array}$ & $\begin{array}{l}\text { Las ciudades y organizaciones han } \\
\text { recibido apoyo. }\end{array}$ \\
\hline & \multirow{8}{*}{ Internos } & $\begin{array}{l}\text { Crisis } \\
\text { socioeconómica }\end{array}$ & & $\begin{array}{l}\text { Crisis } \\
\text { económica }\end{array}$ & $\begin{array}{l}\text { Las regiones se han visto afectas con } \\
\text { crisis económica. }\end{array}$ \\
\hline & & $\begin{array}{l}\text { Condiciones } \\
\text { económicas y } \\
\text { sociales }\end{array}$ & - & $\begin{array}{l}\text { Condiciones } \\
\text { económicas } \\
\text { y sociales }\end{array}$ & $\begin{array}{l}\text { Se diferencia en aspectos relacionados } \\
\text { con el orden público. }\end{array}$ \\
\hline & & & ( & $\begin{array}{l}\text { Burocracia } \\
\text { institucional }\end{array}$ & $\begin{array}{l}\text { Existe una problemática marcada en } \\
\text { España en términos de tramitología para } \\
\text { crear empresas, que afecta a la española }\end{array}$ \\
\hline & & $\begin{array}{l}\text { Infraestructura en } \\
\text { TIC }\end{array}$ & & $\begin{array}{l}\text { Infraestruc- } \\
\text { tura en TIC }\end{array}$ & $\begin{array}{l}\text { Las dos regiones y ciudades cuentan con } \\
\text { muy buena TIC }\end{array}$ \\
\hline & & $\begin{array}{l}\text { Marco regulativo } \\
\text { CTEI }\end{array}$ & 0 & $\begin{array}{l}\text { Marco } \\
\text { regulativo } \\
\text { CTEI }\end{array}$ & \\
\hline & & $\begin{array}{l}\text { Apoyo técnico- } \\
\text { financiero }\end{array}$ & ○ & $\begin{array}{l}\text { Apoyo } \\
\text { técnico- } \\
\text { financiero }\end{array}$ & $\begin{array}{l}\text { Existen dificultades en la financiación en } \\
\text { Colombia en las meso-finanzas y mejoró } \\
\text { las micro y macro finanzas. }\end{array}$ \\
\hline & & SNCTEI & $\bullet$ & $\begin{array}{l}\text { Ecosistema } \\
\text { de empren- } \\
\text { dimiento e } \\
\text { innovación. }\end{array}$ & $\begin{array}{l}\text { El sistema colombiano está en cons- } \\
\text { trucción. España tiene sistema con roles } \\
\text { claros (coordinar-financiar- ejecutar). }\end{array}$ \\
\hline & & $\begin{array}{l}\text { Sistema Regio- } \\
\text { nal de innovación } \\
\text { (SRI) }\end{array}$ & 0 & $\begin{array}{l}\text { Distrito de } \\
\text { innovación }\end{array}$ & $\begin{array}{l}\text { En Medellín se avanza en la estructura de } \\
\text { un SRI. En Barcelona, han desarrollado } \\
\text { en la ciudad un distrito de innovación. }\end{array}$ \\
\hline CONVENCI & NES: & Similitudes $\bigcirc$ & & Diferencias & Aplicación parcial \\
\hline
\end{tabular}

\section{Fuente: elaboración propia}

La incubadora colombiana evolucionó en 15 años de vida como Incubadora de Empresas de Base Tecnológica a un Centro Integral de Servicios Empresariales, y en el caso de la española, en 25 años se transformó de una Incubadora de Empresas de Base Tecnológica a una Agencia de Desarrollo Local. 


\subsection{Influencia de las políticas y programas en el cambio organizacional de las incubadoras}

El modelo organización-entorno tiene tres corrientes de trabajo: los patrones comunitarios, los sistemas de servicios humanos, y los estudios de política pública; se asume la corriente del estudio de las políticas públicas, debido a que los aspectos analizados en esta corriente coinciden con el interés de la institucionalización de las políticas y programas de desarrollo empresarial e innovación, derivados de los planes de desarrollo nacional, regional y local, como se percibe en la siguiente tabla.

Tabla 2. Análisis comparativo por categorías selectivas de las políticas y programas de emprendimiento e innovación

\begin{tabular}{|c|c|c|c|c|c|}
\hline & & $\begin{array}{l}\text { Incubadora } \\
\text { colombiana }\end{array}$ & & $\begin{array}{l}\text { Incubadora } \\
\text { española }\end{array}$ & \\
\hline Niveles & Aspecto & Categorías & $\begin{array}{l}\text { Compara- } \\
\text { tivo }\end{array}$ & Categorías & Análisis descriptivo (1980-2010) \\
\hline \multirow{5}{*}{ Regional } & \multirow{5}{*}{$\begin{array}{l}\text { Progra- } \\
\text { mas }\end{array}$} & $\begin{array}{l}\text { Desarrollo de } \\
\text { actividades } \\
\text { productivas }\end{array}$ & $\bullet$ & $\begin{array}{l}\text { Promoción } \\
\text { compartida } \\
\text { del desarrollo } \\
\text { regional }\end{array}$ & $\begin{array}{l}\text { El marco legal y la distribución política } \\
\text { es distinta en concepto y aplicación } \\
\text { de la autonomía de la constitución } \\
\text { de } 1991 \text { para Colombia y en España } \\
\text { en el año } 1979 \text { con la caída del régi- } \\
\text { men de Franco. Cataluña tiene más } \\
\text { autonomía. }\end{array}$ \\
\hline & & $\begin{array}{l}\text { Generación de } \\
\text { empleo. }\end{array}$ & • & $\begin{array}{l}\text { Fomento a la } \\
\text { creación de } \\
\text { empresas. }\end{array}$ & $\begin{array}{l}\text { Las regiones han trabajado de manera } \\
\text { distinta durante los últimos } 30 \text { años } \\
\text { el tema de la generación de empleo. } \\
\text { Antioquia ha descuidado la creación } \\
\text { de empresas, que aparece en el } 2000 . \\
\text { Cataluña lo trabaja hace } 20 \text { años. }\end{array}$ \\
\hline & & $\begin{array}{l}\text { Fomento del sec- } \\
\text { tor agropecuario } \\
\text { y agroindustrial. }\end{array}$ & $\bullet$ & $\begin{array}{l}\text { Promoción } \\
\text { empresarial } \\
\text { para la } \\
\text { reconversión } \\
\text { industrial. }\end{array}$ & $\begin{array}{l}\text { Al ser Antioquia una región con vo- } \\
\text { cación agropecuaria y agroindustrial, } \\
\text { los programas se han concentrado en } \\
\text { fortalecer dicho sector, sin embargo, } \\
\text { han descuidado el sector servicios y } \\
\text { en él, la reconversión industrial que se } \\
\text { presenta. Cataluña empezó en } 1986 \text { y } \\
\text { ha fortalecido en el sector servicios. }\end{array}$ \\
\hline & & $\begin{array}{l}\text { Fomento tecno- } \\
\text { lógico }\end{array}$ & $\bullet$ & $\begin{array}{l}\text { Desarrollo } \\
\text { tecnológico }\end{array}$ & $\begin{array}{l}\text { La óptica en Antioquia ha estado más } \\
\text { ligada a la incorporación tecnológica. } \\
\text { Cataluña ha trabajado más la adapta- } \\
\text { ción y el desarrollo tecnológico. }\end{array}$ \\
\hline & & $\begin{array}{l}\text { Fomento a la } \\
\text { exportación }\end{array}$ & - & $\begin{array}{l}\text { Internaciona- } \\
\text { lización }\end{array}$ & $\begin{array}{l}\text { La preocupación en Antioquia ha } \\
\text { estado centrada en la exportación de } \\
\text { bienes y servicios. Cataluña que se ha } \\
\text { preocupado por la internacionaliza- } \\
\text { ción, no sólo de productos y servicios, } \\
\text { sino de las empresas y la región. }\end{array}$ \\
\hline
\end{tabular}


Análisis comparativo del cambio organizacional e institucional de dos incubadoras de empresas

\begin{tabular}{|c|c|c|c|c|c|}
\hline & & $\begin{array}{l}\text { Incubadora } \\
\text { colombiana }\end{array}$ & & $\begin{array}{l}\text { Incubadora } \\
\text { española }\end{array}$ & \\
\hline Niveles & Aspecto & Categorías & $\begin{array}{l}\text { Compara- } \\
\text { tivo }\end{array}$ & Categorías & Análisis descriptivo (1980-2010) \\
\hline \multirow{5}{*}{ Regional } & & Sectores y clúster & O & $\begin{array}{l}\text { Sectores y } \\
\text { clúster }\end{array}$ & $\begin{array}{l}\text { Las dos regiones tienen definidos los } \\
\text { sectores y clúster estratégicos }\end{array}$ \\
\hline & & $\begin{array}{l}\text { Productividad y } \\
\text { competitividad. }\end{array}$ & 0 & $\begin{array}{l}\text { Productividad } \\
\text { y competitivi- } \\
\text { dad. }\end{array}$ & $\begin{array}{l}\text { Las dos regiones tienen definidos } \\
\text { los campos de productividad y com- } \\
\text { petitividad. }\end{array}$ \\
\hline & $\begin{array}{l}\text { Progra- } \\
\text { mas }\end{array}$ & $\begin{array}{l}\text { Emprendimiento } \\
\text { y desarrollo } \\
\text { empresarial. }\end{array}$ & - & $\begin{array}{l}\text { Economía del } \\
\text { conocimiento, } \\
\text { innovación y } \\
\text { desarrollo em- } \\
\text { presarial. }\end{array}$ & $\begin{array}{l}\text { La tardía incorporación y ejecución } \\
\text { de políticas de emprendimiento e in- } \\
\text { novación en Colombia, los programas } \\
\text { apenas se desarrollan en Antioquia. } \\
\text { Cataluña, desarrolla más la economía } \\
\text { del conocimiento y la innovación en } \\
\text { los emprendimientos dinámicos y } \\
\text { tradicionales. }\end{array}$ \\
\hline & & $\begin{array}{l}\text { Planeación y } \\
\text { ejecución de la } \\
\text { CTEI }\end{array}$ & 0 & $\begin{array}{l}\text { Fomento CTEI } \\
\text { y la propiedad } \\
\text { intelectual. }\end{array}$ & $\begin{array}{l}\text { Las dos ciudades y regiones tienen } \\
\text { establecidas de manera formal las } \\
\text { políticas y programas de CTEI. }\end{array}$ \\
\hline & & & ( & $\begin{array}{l}\text { Reforma del } \\
\text { Estatuto de } \\
\text { Autonomía de } \\
\text { Cataluña }\end{array}$ & $\begin{array}{l}\text { Cataluña ha contado y cuenta con } \\
\text { un mecanismo normativo y legal } \\
\text { de autonomía que facilita realizar } \\
\text { modificaciones administrativas y } \\
\text { financieras, en pro del desarrollo } \\
\text { económico y empresarial de la región. }\end{array}$ \\
\hline \multirow{6}{*}{ Local } & Políticas & $\begin{array}{l}\text { Visión futura de } \\
\text { ciudad }\end{array}$ & \multirow{4}{*}{0} & $\begin{array}{l}\text { Visión futura d } \\
\text { ciudad }\end{array}$ & $\begin{array}{l}\text { Las dos regiones tienen definida de } \\
\text { forma clara su apuesta de futuro }\end{array}$ \\
\hline & & Plan de desarrollo & & $\begin{array}{l}\text { Plan de desa- } \\
\text { rrollo }\end{array}$ & $\begin{array}{l}\text { Las dos ciudades y regiones cuen- } \\
\text { tan con un plan metropolitano de } \\
\text { desarrollo }\end{array}$ \\
\hline & & $\begin{array}{l}\text { Generación de } \\
\text { empleo }\end{array}$ & & $\begin{array}{l}\text { Generación de } \\
\text { empleo }\end{array}$ & $\begin{array}{l}\text { Las dos regiones tienen definida } \\
\text { claramente su apuesta para generar } \\
\text { empleo }\end{array}$ \\
\hline & & $\begin{array}{l}\text { Cultura } \\
\text { empresarial }\end{array}$ & & $\begin{array}{l}\text { Cultura em- } \\
\text { presarial }\end{array}$ & $\begin{array}{l}\text { Las dos regiones tienen establecido } \\
\text { una política de cultura emprendedora }\end{array}$ \\
\hline & & $\begin{array}{l}\text { Fortalecimiento } \\
\text { económico y } \\
\text { empresarial. }\end{array}$ & - & $\begin{array}{l}\text { Fortalecimien- } \\
\text { to económico } \\
\text { y empresarial. }\end{array}$ & $\begin{array}{l}\text { En Medellín está más ligado a generar } \\
\text { más desarrollo empresarial para } \\
\text { luego si concentrarse en el desarrollo } \\
\text { económico, sin embargo, esta misma } \\
\text { lógica ya la aplicó y superó Barcelona, } \\
\text { España. }\end{array}$ \\
\hline & & $\begin{array}{l}\text { Medellín Cities y } \\
\text { su área metropo- } \\
\text { litana. }\end{array}$ & 0 & $\begin{array}{l}\text { Barcelona Ci- } \\
\text { ties y su área } \\
\text { metropolita- } \\
\text { na. }\end{array}$ & $\begin{array}{l}\text { Las dos ciudades tienen en las polí- } \\
\text { ticas estas dos iniciativas de ciudad. }\end{array}$ \\
\hline
\end{tabular}




\begin{tabular}{|c|c|c|c|c|c|}
\hline & & \multirow[b]{3}{*}{$\begin{array}{c}\text { Compara- } \\
\text { tivo }\end{array}$} & \multirow{3}{*}{$\begin{array}{c}\text { Incubadora } \\
\text { española } \\
\text { Categorías }\end{array}$} & \\
\hline & & \multirow{2}{*}{$\begin{array}{l}\text { Incubadora } \\
\text { colombiana } \\
\text { Categorías }\end{array}$} & & & \multirow[b]{2}{*}{ Análisis descriptivo (1980-2010) } \\
\hline \multirow[t]{2}{*}{ Niveles } & \multirow[t]{2}{*}{ Aspecto } & & & & \\
\hline & & $\begin{array}{l}\text { Modelo de ciudad } \\
\text { innovadora. }\end{array}$ & 0 & $\begin{array}{l}\text { Modelo de } \\
\text { ciudad del co- } \\
\text { nocimiento e } \\
\text { innovación }\end{array}$ & $\begin{array}{l}\text { Las dos ciudades tienen en las políti- } \\
\text { cas estas dos estrategias de ciudad. }\end{array}$ \\
\hline \multirow{8}{*}{ Local } & \multirow{8}{*}{$\begin{array}{l}\text { Progra- } \\
\text { mas }\end{array}$} & $\begin{array}{l}\text { Infraestructura } \\
\text { urbana, física y } \\
\text { tecnológica. }\end{array}$ & O & $\begin{array}{l}\text { Infraestruc- } \\
\text { tura urbana, } \\
\text { física y tecno- } \\
\text { lógica. }\end{array}$ & $\begin{array}{l}\text { Las dos regiones cuentan con muy } \\
\text { buena infraestructura urbana, física } \\
\text { y tecnológica. }\end{array}$ \\
\hline & & $\begin{array}{l}\text { Medellín la más } \\
\text { educada }\end{array}$ & 0 & $\begin{array}{l}\text { Proyecto edu- } \\
\text { cativo de ciu- } \\
\text { dad. }\end{array}$ & $\begin{array}{l}\text { Las dos regiones cuentan con proyec- } \\
\text { tos educativos de ciudad }\end{array}$ \\
\hline & & $\begin{array}{l}\text { Ciudad producti- } \\
\text { va y competitiva. }\end{array}$ & $\bigcirc$ & $\begin{array}{l}\text { Productividad } \\
\text { y competitivi- } \\
\text { dad en secto- } \\
\text { res estratégi- } \\
\text { cos. }\end{array}$ & $\begin{array}{l}\text { Las dos regiones establecieron polí - } \\
\text { ticas y programas de productividad y } \\
\text { competitividad en sectores estratégi- } \\
\text { cos orientados a las fortalezas locales } \\
\text { y regionales. }\end{array}$ \\
\hline & & Cultura E & 0 & $\begin{array}{l}\text { Metrópolis } \\
\text { emprendedora }\end{array}$ & $\begin{array}{l}\text { Las dos ciudades le apostaron hace } \\
15 \text { años a políticas de cultura em- } \\
\text { prendedora. }\end{array}$ \\
\hline & & Ciudad Clúster & 0 & $\begin{array}{l}\text { Clúster de cla- } \\
\text { se mundial }\end{array}$ & $\begin{array}{l}\text { Las dos regiones cuentan con estra- } \\
\text { tegias de ciudad clúster. }\end{array}$ \\
\hline & & $\begin{array}{l}\text { Ciudad innova- } \\
\text { dora }\end{array}$ & • & $\begin{array}{l}\text { Ciudad del co- } \\
\text { nocimiento }\end{array}$ & $\begin{array}{l}\text { Los dos programas tienen la orienta- } \\
\text { ción de crear en empresas con con- } \\
\text { tenido en conocimiento e innovación } \\
\text { y acompañar a las ya existentes en el } \\
\text { desarrollo de capacidades de innova- } \\
\text { ción. Sin embargo, en Medellín está } \\
\text { más orientado a la comercialización } \\
\text { de productos y servicios, mientras } \\
\text { en Barcelona, se orienta más hacia la } \\
\text { propiedad intelectual y la comercia- } \\
\text { lización de conocimiento científico y } \\
\text { tecnológico. }\end{array}$ \\
\hline & & $\begin{array}{l}\text { Agencia de } \\
\text { promoción de la } \\
\text { ciudad. }\end{array}$ & O & $\begin{array}{l}\text { Agencia de } \\
\text { promoción de } \\
\text { la ciudad. }\end{array}$ & $\begin{array}{l}\text { Las dos ciudades cuentan con agen- } \\
\text { cias de promoción nacional e interna- } \\
\text { cional de la región. }\end{array}$ \\
\hline & & $\begin{array}{l}\text { Medellín ciudad } \\
\text { de negocios. }\end{array}$ & 0 & $\begin{array}{l}\text { Barcelona ciu- } \\
\text { dad de nego- } \\
\text { cios. }\end{array}$ & $\begin{array}{l}\text { Las dos regiones cuentan con estra- } \\
\text { tegias de ciudad de negocios. }\end{array}$ \\
\hline & & & - & $\begin{array}{l}\text { Barcelona di- } \\
\text { gital }\end{array}$ & $\begin{array}{l}\text { Barcelona quiere ser una ciudad } \\
\text { digital, donde se transversalice las TIC } \\
\text { en el aparato productivo y académico } \\
\text { de la ciudad. }\end{array}$ \\
\hline
\end{tabular}


Análisis comparativo del cambio organizacional e institucional de dos incubadoras de empresas

\begin{tabular}{|c|c|c|c|c|c|}
\hline & & $\begin{array}{l}\text { Incubadora } \\
\text { colombiana }\end{array}$ & & $\begin{array}{c}\text { Incubadora } \\
\text { española }\end{array}$ & \\
\hline \multirow[t]{3}{*}{ Niveles } & Aspecto & Categorías & $\begin{array}{c}\text { Compara- } \\
\text { tivo }\end{array}$ & Categorías & Análisis descriptivo (1980-2010) \\
\hline & & & ( ) & $\begin{array}{l}\text { Zona de inno- } \\
\text { vación y em- } \\
\text { prendimiento. }\end{array}$ & $\begin{array}{l}\text { CTEI como espacio físico, logístico e } \\
\text { interacción de actores y sistemas en } \\
\text { función del conocimiento, con foco } \\
\text { en servicios de valor agregado. }\end{array}$ \\
\hline & & & (1) & $\begin{array}{l}\text { Ciudad de } \\
\text { atracción y } \\
\text { retención de } \\
\text { talentos. }\end{array}$ & $\begin{array}{l}\text { Programa de captura, atracción, } \\
\text { formación y retención de talentos } \\
\text { que contribuyan el desarrollo local } \\
\text { endógeno de la ciudad. }\end{array}$ \\
\hline \multicolumn{2}{|c|}{ CONVENCIONES: } & Similitudes & & Diferencias & Aplicación parcial \\
\hline
\end{tabular}

Fuente: elaboración propia.

Se reafirma que las políticas y programas de emprendimiento y de CTEI en los dos entornos estudiados durante los últimos treinta años han evolucionado en cantidad y calidad. Esto significa que los gobiernos internacionales, nacionales, regionales y locales están preocupados por generar condiciones políticas, sociales y económicas para la generación de empleo, vía creación de empresas tradicionales, empresas de base tecnológica, creativas, de valor agregado y de contenido innovador.

\subsection{Incorporación de las políticas y programas de desarrollo empresarial e innovación en las dos organizaciones}

Fue necesario hacer una contextualización histórica, social y económica a partir de los factores internos y externos, y de las políticas y los programas de emprendimiento e innovación, que permitiera observar los acontecimientos que inciden en el desarrollo de los contextos donde surgieron y se desarrollaron estas dos organizaciones (ver tabla 3).

Tabla 3. Análisis comparativo por categorías selectivas de la incorporación de las políticas y los programas de desarrollo empresarial e innovación en las dos incubadoras

\begin{tabular}{|c|c|c|c|c|c|}
\hline & \multicolumn{2}{|c|}{ Colombia } & & \multicolumn{2}{|c|}{ España } \\
\hline & Programas & $\begin{array}{l}\text { Incorporación de } \\
\text { nuevos servicios y } \\
\text { actividades en la } \\
\text { incubadora }\end{array}$ & $\begin{array}{l}\text { Com- } \\
\text { para- } \\
\text { tivo }\end{array}$ & Programas & $\begin{array}{c}\text { Incorporación de nuevas } \\
\text { actividades y servicios en } \\
\text { la incubadora }\end{array}$ \\
\hline $\begin{array}{l}\text { Política 1: } \\
\text { Promoción } \\
\text { empresarial }\end{array}$ & $\begin{array}{l}\text { Marco legal CTEI } \\
\text { y emprendi- } \\
\text { miento }\end{array}$ & $\begin{array}{l}\text { Creación de } \\
\text { empresas }\end{array}$ & O & $\begin{array}{l}\text { Marco legal CTEI y } \\
\text { emprendimiento }\end{array}$ & $\begin{array}{l}\text { Creación de empre- } \\
\text { sas. }\end{array}$ \\
\hline
\end{tabular}




\begin{tabular}{|c|c|c|c|c|c|}
\hline & \multicolumn{2}{|c|}{ Colombia } & \multirow[b]{2}{*}{$\begin{array}{l}\text { Com- } \\
\text { para- } \\
\text { tivo }\end{array}$} & \multicolumn{2}{|c|}{ España } \\
\hline & Programas & $\begin{array}{l}\text { Incorporación de } \\
\text { nuevos servicios y } \\
\text { actividades en la } \\
\text { incubadora }\end{array}$ & & Programas & $\begin{array}{l}\text { Incorporación de nuevas } \\
\text { actividades y servicios en } \\
\text { la incubadora }\end{array}$ \\
\hline & $\begin{array}{l}\text { Cultura empre- } \\
\text { sarial }\end{array}$ & $\begin{array}{l}\text { Fortalecimiento } \\
\text { empresarial }\end{array}$ & $\bullet$ & Cultura empresarial & $\begin{array}{l}\text { Crecimiento empre- } \\
\text { sarial }\end{array}$ \\
\hline & $\begin{array}{l}\text { Dirección de } \\
\text { desarrollo } \\
\text { empresarial. }\end{array}$ & $\begin{array}{l}\text { Banca y ruedas } \\
\text { de inversión }\end{array}$ & O & $\begin{array}{l}\text { Fortalecimiento desarro- } \\
\text { llo empresarial }\end{array}$ & Acceso al empleo \\
\hline & $\begin{array}{l}\text { Desarrollo } \\
\text { empresarial e } \\
\text { innovación }\end{array}$ & $\begin{array}{l}\text { Aceleradora de } \\
\text { negocios }\end{array}$ & • & $\begin{array}{l}\text { Financiación al empren- } \\
\text { dimiento }\end{array}$ & $\begin{array}{l}\text { Promoción econó- } \\
\text { mica }\end{array}$ \\
\hline & $\begin{array}{l}\text { Medellín ciudad } \\
\text { emprendedora }\end{array}$ & \begin{tabular}{|l} 
Operación \\
programas \\
territoriales de \\
emprendimiento
\end{tabular} & & $\begin{array}{l}\text { Metrópolis emprende- } \\
\text { dora }\end{array}$ & $\begin{array}{l}\text { Cultura emprendedo- } \\
\text { ra y digital }\end{array}$ \\
\hline & $\begin{array}{l}\text { Medellín ciudad } \\
\text { de negocios. }\end{array}$ & $\begin{array}{l}\text { Posicionamiento } \\
\text { de marca }\end{array}$ & O & $\begin{array}{l}\text { Barcelona ciudad de } \\
\text { negocios. }\end{array}$ & $\begin{array}{l}\text { Gestión del capital } \\
\text { humano }\end{array}$ \\
\hline & $\begin{array}{l}\text { Desarrollo CTEI y } \\
\text { emprendimiento }\end{array}$ & $\begin{array}{l}\text { Transferencia del } \\
\text { modelo }\end{array}$ & $\bullet$ & $\begin{array}{l}\text { Estrategia CTEI y em- } \\
\text { prendimiento }\end{array}$ & $\begin{array}{l}\text { Transferencia Tecno- } \\
\text { lógica }\end{array}$ \\
\hline \multirow[t]{7}{*}{$\begin{array}{l}\text { Política 2: } \\
\text { Promoción } \\
\text { económica }\end{array}$} & $\begin{array}{l}\text { Promoción desa- } \\
\text { rrollo económico }\end{array}$ & $\begin{array}{l}\text { La incubadora } \\
\text { sólo apoya la } \\
\text { ejecución de } \\
\text { programas } \\
\text { de desarrollo } \\
\text { empresarial y no } \\
\text { de promoción } \\
\text { económica }\end{array}$ & $\bullet$ & $\begin{array}{l}\text { Agencia catalana de } \\
\text { competitividad }\end{array}$ & \multirow{7}{*}{$\begin{array}{l}\text { La incubadora co-crea } \\
\text { y co-produce junto } \\
\text { con el Ayuntamiento } \\
\text { desde su fundación } \\
\text { todas las políticas y } \\
\text { programas desarrollo } \\
\text { empresarial econó- } \\
\text { mica, donde cuatro } \\
\text { de las actividades } \\
\text { principales (acceso } \\
\text { al empleo, promoción } \\
\text { económica, cultura } \\
\text { digital y gestión del } \\
\text { capital humano), se } \\
\text { encargan de poner en } \\
\text { marcha ésta política. }\end{array}$} \\
\hline & $\begin{array}{l}\text { Consejo Nacional } \\
\text { de Competiti- } \\
\text { vidad }\end{array}$ & & & $\begin{array}{l}\text { Promoción desarrollo } \\
\text { económico }\end{array}$ & \\
\hline & $\begin{array}{l}\text { Fortalecimiento } \\
\text { económico y } \\
\text { empresarial }\end{array}$ & & $\bullet$ & $\begin{array}{l}\text { Departamento de econo- } \\
\text { mía y conocimiento }\end{array}$ & \\
\hline & $\begin{array}{l}\text { Medellín Cities y } \\
\text { área metropoli- } \\
\text { tana. }\end{array}$ & & \multirow[t]{2}{*}{ O } & $\begin{array}{l}\text { Barcelona Cities y área } \\
\text { metropolitana. }\end{array}$ & \\
\hline & $\begin{array}{l}\text { Ciudad producti- } \\
\text { va y competitiva. }\end{array}$ & & & $\begin{array}{l}\text { Productividad y compe- } \\
\text { titividad }\end{array}$ & \\
\hline & $\begin{array}{l}\text { Medellín ciudad } \\
\text { Clúster }\end{array}$ & & \multirow[b]{2}{*}{0} & $\begin{array}{l}\text { Sectores y Clúster } \\
\text { estratégicos }\end{array}$ & \\
\hline & $\begin{array}{l}\text { Agencia de } \\
\text { promoción de la } \\
\text { ciudad }\end{array}$ & & & $\begin{array}{l}\text { Agencia de promoción de } \\
\text { la ciudad }\end{array}$ & \\
\hline
\end{tabular}


Análisis comparativo del cambio organizacional e institucional de dos incubadoras de empresas

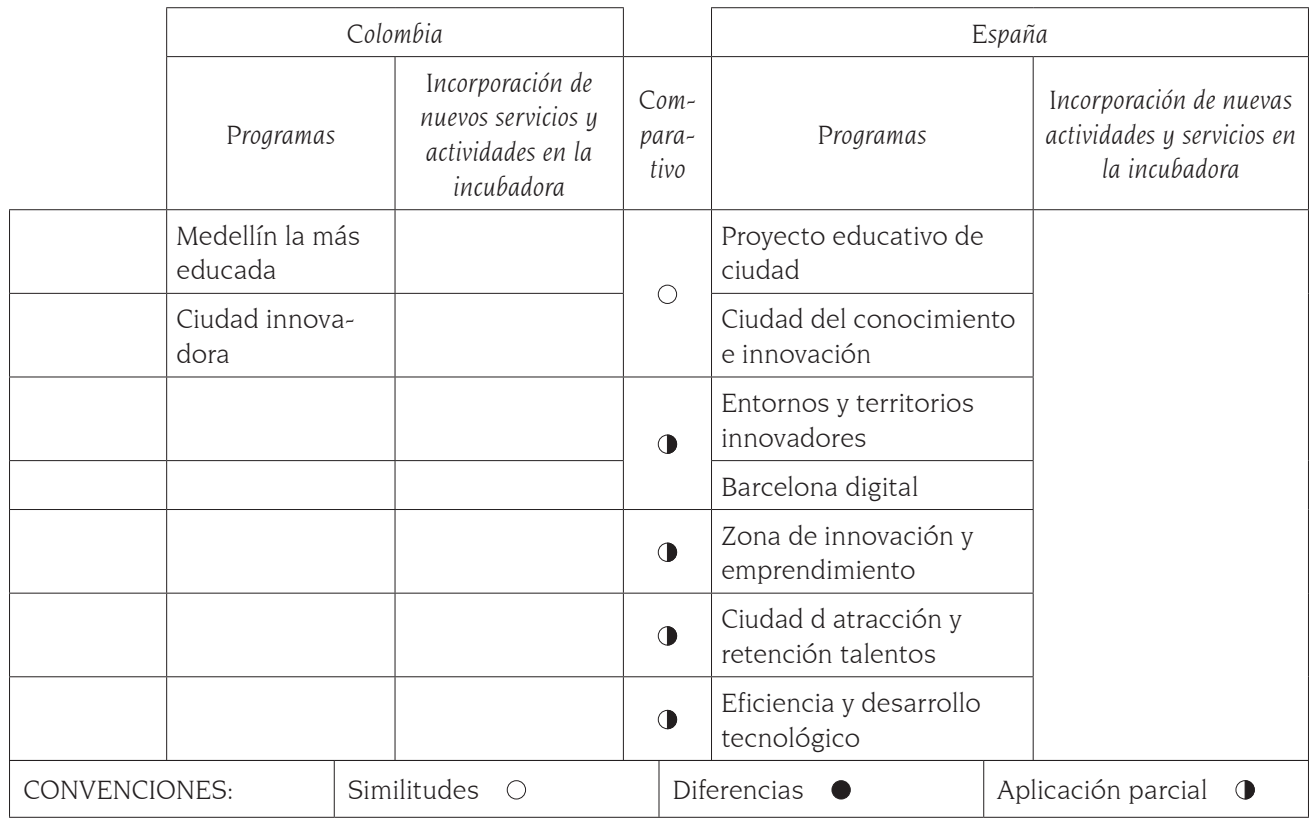

Fuente: elaboración propia

La tabla anterior hace evidente que en los dos entornos estudiados, se han generado políticas de desarrollo empresarial y económico, que incluyen una serie de programas que crean las condiciones socioeconómicas de cada país, región y localidad, en términos de desarrollo local endógeno, donde, además de preocuparse por la generación de espacios propicios para la creación y fortalecimiento empresarial, también se denota un interés marcado por posicionar las ciudades internacionalmente, vía productividad y competitividad empresarial, conocimiento e innovación.

Esta dinámica política y programática se diferencia en los dos contextos investigados por los períodos de aplicación; es decir, las condiciones políticas, económicas y sociales emergen primero y con mayor fuerza en España, principalmente en Barcelona, en la década de 1990, y luego en Colombia, y de forma concreta en Medellín, durante la década del 2000. Esta diferencia marca un desfase sustancial en el desarrollo de las políticas y programas institucionalizados en las dos organizaciones.

\subsection{Proceso de institucionalización de las políticas y programas de desarrollo empresarial e innovación en dos organizaciones}

En el análisis del proceso de institucionalización de las políticas y programas de desarrollo empresarial y desarrollo económico de una incubadora respecto de la 
otra, es necesario retomar de manera selectiva el proceso de incorporación de las políticas y programas en la incubadora colombiana y en la española, con el fin de analizar cuáles han podido institucionalizarse; la siguiente tabla evidencia que las políticas y los programas de desarrollo empresarial, institucionalizados en los dos entornos (Medellín y Barcelona) y en las dos organizaciones, por un lado, son similares en su concepción y ejecución, y por otro, son diferentes en su proceso de desarrollo y maduración, debido a que en Barcelona, además de tener apoyo directo del Ayuntamiento, también se implementa este tipo de acciones en la ciudad desde hace más de diez años.

Tabla 4. Análisis comparativo por categorías selectivas de la institucionalización de las políticas y los programas de desarrollo empresarial en las dos incubadoras

\begin{tabular}{|c|c|c|c|c|c|}
\hline & \multicolumn{2}{|c|}{ Colombia } & \multirow[b]{2}{*}{ Comparativo } & \multicolumn{2}{|c|}{ España } \\
\hline & Programas & $\begin{array}{l}\text { Institucionalización } \\
\text { de políticas y } \\
\text { programas en la } \\
\text { incubadora }\end{array}$ & & Programas & $\begin{array}{c}\text { Institucionalización } \\
\text { de políticas y } \\
\text { programas en la } \\
\text { incubadora }\end{array}$ \\
\hline \multirow{7}{*}{$\begin{array}{l}\text { Política 1: } \\
\text { Promoción } \\
\text { empresa- } \\
\text { rial }\end{array}$} & $\begin{array}{l}\text { Marco legal de la } \\
\text { CTEI y el empren- } \\
\text { dimiento }\end{array}$ & $\begin{array}{l}\text { Creación de em- } \\
\text { presas }\end{array}$ & 0 & $\begin{array}{l}\text { Marco legal de la } \\
\text { CTEI y el empren- } \\
\text { dimiento }\end{array}$ & $\begin{array}{l}\text { Creación de em- } \\
\text { presas }\end{array}$ \\
\hline & $\begin{array}{l}\text { Cultura empre- } \\
\text { sarial }\end{array}$ & $\begin{array}{l}\text { Fortalecimiento } \\
\text { empresarial }\end{array}$ & 0 & $\begin{array}{l}\text { Cultura empre- } \\
\text { sarial }\end{array}$ & $\begin{array}{l}\text { Crecimiento em- } \\
\text { presarial }\end{array}$ \\
\hline & $\begin{array}{l}\text { Desarrollo em- } \\
\text { presarial e inno- } \\
\text { vación }\end{array}$ & $\begin{array}{l}\text { Banca y ruedas } \\
\text { de inversión }\end{array}$ & - & $\begin{array}{l}\text { Fortalecimiento } \\
\text { del desarrollo } \\
\text { empresarial }\end{array}$ & Acceso al empleo \\
\hline & $\begin{array}{l}\text { Dirección de de- } \\
\text { sarrollo empre- } \\
\text { sarial. }\end{array}$ & $\begin{array}{l}\text { Aceleradora de } \\
\text { negocios }\end{array}$ & - & $\begin{array}{l}\text { Estímulos y fi- } \\
\text { nanciación al } \\
\text { emprendimiento }\end{array}$ & $\begin{array}{l}\text { Promoción eco- } \\
\text { nómica }\end{array}$ \\
\hline & $\begin{array}{l}\text { Medellín ciudad } \\
\text { emprendedora }\end{array}$ & $\begin{array}{l}\text { Operación terri- } \\
\text { torial de empren- } \\
\text { dimiento. }\end{array}$ & 0 & $\begin{array}{l}\text { Metrópolis em- } \\
\text { prendedora }\end{array}$ & $\begin{array}{l}\text { Cultura empren- } \\
\text { dedora y digital }\end{array}$ \\
\hline & $\begin{array}{l}\text { Medellín ciudad } \\
\text { de negocios. }\end{array}$ & $\begin{array}{l}\text { Posicionamiento } \\
\text { de marca }\end{array}$ & $\bullet$ & $\begin{array}{l}\text { Barcelona ciudad } \\
\text { de negocios. }\end{array}$ & $\begin{array}{l}\text { Gestión del capi- } \\
\text { tal humano }\end{array}$ \\
\hline & $\begin{array}{l}\text { Desarrollo de } \\
\text { CTEI y empren- } \\
\text { dimiento }\end{array}$ & $\begin{array}{l}\text { Transferencia del } \\
\text { modelo }\end{array}$ & $\bigcirc$ & $\begin{array}{l}\text { Estrategias de } \\
\text { CTEI y empren- } \\
\text { dimiento. }\end{array}$ & $\begin{array}{l}\text { Transferencia } \\
\text { Tecnológica }\end{array}$ \\
\hline \multicolumn{2}{|c|}{ CONVENCIONES: } & Similitudes $\bigcirc$ & Diferencias & \multicolumn{2}{|c|}{ Aplicación parcial } \\
\hline
\end{tabular}

Fuente: elaboración propia

Por otra parte, las políticas y los programas institucionalizados están relacionados con el fomento y la promoción de la CTEI, la cultura emprendedora, la creación de empresas, el fortalecimiento empresarial, la transferencia tecnológica y de cono- 
cimiento de los dos modelos de acompañamiento al emprendedor y, finalmente, un aspecto que también incide en la institucionalización es la imagen que se tiene sobre las dos ciudades que son reconocidas como ciudades emprendedoras e innovadoras.

\section{CONCLUSIONES}

Se confirmó que la aplicación del enfoque teórico-analítico fue útil y pertinente para definir los factores internos y externos, y las políticas y programas de desarrollo empresarial e innovación, que han impactado a ambas incubadoras, en el campo organizacional, así como a los incubados y a las empresas incubadas en lo organizacional; también permitió establecer con claridad la relación entre la institucionalización de las políticas y programas de desarrollo empresarial e innovación con el cambio organizacional e institucional y el campo del emprendimiento.

Se puede afirmar que las perspectivas teóricas con las que se construyó el enfoque analítico, para estudiar los dos casos, permitieron abordar el cambio de las incubadoras de empresas y comprender los elementos fundamentales, así como su proceso de institucionalización. Además, los resultados demuestran y explicitan el carácter dinámico y la complejidad del proceso de cambio organizacional e institucional de las incubadoras en contextos similares en el ámbito internacional, pero sustantivamente diferentes en los ámbitos nacional y local.

El análisis de los ambientes interno y externo de las dos incubadoras desde una perspectiva multidisciplinaria contribuyó a la comprensión y explicación del cambio organizacional e institucional que han experimentado durante su evolución, y, según los resultados de esta investigación, muestra que tanto los factores internos y externos, como la institucionalización de las políticas y programas en materia de emprendimiento e innovación constituyen los principales vectores de cambio organizacional e institucional, tanto para las organizaciones del Sistema Nacional de Ciencia Tecnología e Innovación (SNCTEI) en Medellín, como del Sistema Nacional de Innovación (SIN) en Barcelona; en ambos casos la transformación ha sido individual y también colectiva.

Se constata que en este proceso no se pueden ignorar los factores internos y externos, ni mucho menos las políticas y programas que crearon las condiciones que condujeron al cambio y la transformación de las dos incubadoras en centro integral de servicios empresariales (la colombiana) y en agencia de desarrollo local (la española) respectivamente. Por tanto, la influencia de los factores y las políticas y programas exige desarrollo y evolución recíprocos entre el determinismo del entorno y el razonamiento estratégico de los actores, de manera colectiva y organizada. Los 
enfoques teóricos no son explícitos en estos términos; de ahí que se requiera una extensión de estos, en su aplicación al análisis de toda la incubadora (incubadoincubadora-red-comunidad).

Se concluye que las dos incubadoras han tenido que adaptarse a las condiciones del entorno; y en este proceso de cambio organizacional e institucional, ambas incubadoras han transformado dicho entorno, al impulsar la innovación en el modelo de acompañamiento e incubación de empresas, por medio de una red y/o entorno innovador propicio para el emprendimiento observable tanto en Medellín, como en Barcelona. Futuras investigaciones podrían estudiar otras organizaciones del sistema con el fin de comprender su cambio y evolución en el tiempo de los actores y de los sistemas, y mejorar su desempeño.

\section{BIBLIOGRAFÍA}

Anderson, B. B. y Al-Mubaraki, H. (2012). The Gateway Innovation Center: exploring key elements of developing a business incubator. En: World Journal of Entrepreneurship, Management and Sustainable Development, Vol. 8, N 4, pp. 208-216.

Battilana, J. y Casciaro, T. (2012). Change agents, networks, and institutions: A contingency theory of organizational change. En: Academy of Management Journal, Vol. 55, N² 2, pp. 381-398.

Crozier, M. y Friedberg, E. (1990). El actor y el sistema. Las contradicciones de la acción colectiva. México D. F.: Patria S. A., 390p.

Cooper, C. E; Hamel, S. A. y Connaughton, S. L. (2012). Motivations and obstacles to networking in a university business incubator. En: The Journal of Technology Transfer, Vol. 37, N. ${ }^{\circ}$, pp. $433-453$.

Eisenhardt, K. M. (1989). Building Theories from Case Study Research. En: Academy of Management Review, Vol. 14, N. ${ }^{\circ}$, pp. 532-550.

GEM. (2012). Global Entrepreneurship Monitor: Informe GEM España 2012. España: IE Business School, Ministerio de Economía-España, GEM, 148p.

GEM (2015). GEM Colombia 2006-2013. Cali: CDEE, 154p.

Hackett, S. M. y Dilts, D. M. (2004a). A Systematic Review of Business Incubation Research. En: The Journal of Technology Transfer, Vol. 29, $\mathrm{N}^{\circ} 1$, pp. 55-82.

Hackett, S. M. y Dilts, D. M. (2004b). A Real Options-Driven Theory of Business Incubation. En: The Journal of Technology Transfer, Vol. 29, Nº1, pp. 41-54.

Hansen, M.T.; Cresbrough, H.W.; Nohria, N. y Sull, D.N. (2000). Networked incubators: hosthouses of the new economy. En: Harvard Business Review, Vol. 78, N 5, pp. 74-84.

Meny, Y. y Thoening, J. (1992). Las políticas públicas. Barcelona, Editorial Ariel, S. A., pp. 109-218.

Meyer, J. W. y Scott, W. R. (1992). Organizational Environments: Ritual and Rationality. Londres: Sage Publications, 302p. 
Monnier, E. (1992). Evaluations de l'action des pouvoirs publics (2da ed.). París, Edition Economica.

Muller, P. (2006). Las políticas públicas. Bogotá D. C.: Universidad Externado de Colombia.

OECD. (2009). Promoting entrepreneurship, employment and business competitiveness. The Experience of Barcelona. París; OECD Local Economic and Employment Development (LEED) Programme, 94p.

Peña, I. (2004). Business Incubation Centers and New Firm Growth in the Basque Country. En: Small Business Economics, Vol. 22, N 3-4, pp. 223-236.

Peters, G. B. (2004). Cambios en la naturaleza de la Administración Pública: De las preguntas sencillas a las respuestas difíciles, pp. 69-95. En: Pardo, M. C. (Ed.), De la Administración Pública a la gobernanza. México D. F., El Colegio de México, Centro de Estudios Internacionales, 227p.

Ramírez, G.; Vargas, G. y De la Rosa, A. (2011). Estudios organizacionales y administración. Contrastes y complementariedades: Caminando hacia el eslabón perdido. En: Revista Electrónica Forum Doctoral, Vol. 3, pp. 7-51.

Scillitoe, J. L. y Chakrabarti, A. K. (2010). The role of incubator interactions in assisting new ventures. En: Technovation, Vol. 30, Nº 3, pp. 155-167.

Scott, W. R. (1995). Institutions and organizations (2da ed.). Londres: Sage Publications, 280p.

Tsai, F; Hsieh, L; Fang, S; y Lin, J. (2009). The co-evolution of business incubation and national innovation systems in Taiwan. En: Technological Forecasting and Social Change, Vol. 76, $N^{\circ}$ 5, pp. 629-643.

Yin, R. K. (2003). Case Study Research: Design and Methods. Thousand Oaks, CA, Sage Publications, 240p. 


\section{ANEXOS}

\section{ANEXO A. CUESTIONARIO ENTREVISTA DIRECTIVOS}

CUESTIONARIO DE LA ENTREVISTA PERSONAL REALIZADA A LOS DIRECTIVOS DE LAS INCUBADORAS DE EMPRESAS, SOBRE EL ORIGEN, TRAYECYORIA, CARACTERÍSTICAS Y FACTORES INTERNOS Y EXTERNOS DE LA ORGANIZACIÓN EN EL PROCESO DE CAMBIO

Objetivo de la investigación: Describir los factores internos y externos que inciden en el cambio de la incubadora de empresas CRÉAME, en Medellín, Colombia (1996-2010) y Barcelona Activa, en Barcelona, España (1986-2010), mediante el caso de estudio múltiple, para el análisis del cambio organizacional e institucional de las incubadoras de empresas objeto de estudio.

\section{SECCIÓN I: Origen, trayectoria y características de la incubadora en el proceso de cambio}

a) Información general sobre la incubadora

1. Origen de la incubadora

2. Trayectoria de la incubadora

\section{SECCIÓN II: Factores internos}

b) Información específica sobre los factores internos y los servicios de apoyo al incubado que ofrece la incubadora.

3. ¿Cuáles son las características principales de los productos o servicios que ofrece la organización?

4. ¿Qué facilidad ofrece la organización a los emprendedores para acceder a los recursos y servicios?

5. Para usted ¿cuáles son los factores clave de éxito de la organización?

\section{SECCIÓN III: Factores externos}

c) Incidencia de los factores externos, políticas y programas en la incubadora

6. ¿Qué opinión le merece la puesta en marca de medida de asistencia y apoyo a la creación de empresas durante los últimos años en la ciudad?

7. De las anteriores medidas de apoyo, ¿cuáles considera que han incidido en la organización?

8. ¿Qué cambios significativos ha notado en la ciudad y la organización, en términos de creación de empresas y desarrollo empresarial? 


\section{ANEXO B. CUESTIONARIO ENTREVISTA EMPLEADOS}

CUESTIONARIO DE LA ENTREVISTA PERSONAL REALIZADA A LOS EMPLEADOS DE LASINCUBADORAS DE EMPRESAS, SOBRE EL ORIGEN, TRAYECYORIA, CARACTERÍSTICAS Y FACTORES INTERNOS Y EXTERNOS DE LA ORGANIZACIÓN EN EL PROCESO DE CAMBIO

Objetivo de la investigación: Describir los factores internos y externos que inciden en el cambio de la incubadora de empresas CRÉAME, en Medellín, Colombia (1996-2010) y Barcelona Activa, en Barcelona, España (1986-2010), mediante el caso de estudio múltiple, para el análisis del cambio organizacional e institucional de las incubadoras de empresas objeto de estudio.

\section{SECCIÓN I: Origen, trayectoria y características de la incubadora en el proceso de cambio}

a) Información general sobre la incubadora

1. Origen de la incubadora

2. Trayectoria de la incubadora

\section{SECCIÓN II: Factores internos}

b) Información específica sobre los factores internos y los servicios de apoyo al incubado que ofrece la incubadora.

3. ¿Cuáles son las características principales de los productos o servicios que ofrece la organización?

4. La organización que usted representa, ¿qué programas o proyectos específicos de incubación ofrece?

5. ¿Cómo opera técnica y financieramente el modelo de la incubadora? ¿El modelo ha cambiado?

6. ¿Qué facilidad ofrece la organización a los emprendedores para acceder a los recursos y servicios?

7. Para usted ¿cuáles son los factores clave de éxito de la organización?

8. ¿Qué mejoras propondría con relación a los productos y servicios de apoyo a la incubación de empresas existente en la organización?

\section{SECCIÓN III: Factores externos}

c) Incidencia de los factores externos, políticas y programas en la incubadora

9. ¿Qué opinión le merece la puesta en marca de medida de asistencia y apoyo a la creación de empresas durante los últimos años en la ciudad?

10. De las anteriores medidas de apoyo, ¿cuáles considera que han incidido en la organización?

11. ¿Qué cambios significativos ha notado en la ciudad y la organización, en términos de creación de empresas y desarrollo empresarial? 


\section{ANEXO C. CUESTIONARIO ENTREVISTA A INCUBADOS}

CUESTIONARIO DE LA ENTREVISTA PERSONAL REALIZADA A LOS INCUBADOS DE LA INCUBADORA DE EMPRESAS, SOBRE LAS FACTORES, CARACTERÍSTICAS, FUNCIONES Y ROLES DE LA ORGANIZACIÓN EN EL PROCESO DE CAMBIO

Objetivo de la investigación: Describir los factores internos y externos que inciden en el cambio de la incubadora de empresas CRÉAME, en Medellín, Colombia (1996-2010) y Barcelona Activa, en Barcelona, España (1986-2010), mediante el caso de estudio múltiple, para el análisis del cambio organizacional e institucional de las incubadoras de empresas objeto de estudio.

\section{SECCIÓN I: Características, funciones y roles.}

a) Información general sobre la empresa y emprendedores-as (responder en los recuadros)

1. Nombre de la empresa

2. Actividad de la empresa

3. Año de fundación

4. Perfil emprendedor-a

5. Número de empleados de la empresa (fundación -actualidad)

\section{SECCIÓN II: Factores internos}

b) Información específica sobre la relación con Barcelona Activa (BA)

6. ¿Por qué y cómo llegó la empresa a BA?

7. ¿Qué aspectos tuvo en cuenta para seleccionar BA?

8. ¿Cómo fue su proceso de selección y vinculación a BA?

9. ¿Cuáles son los beneficios que ha obtenido de BA?

c) Importancia y valoración general de los servicios y productos de apoyo recibidos por parte de BA

10. ¿Cuál es su percepción sobre los servicios y productos que ofrece BA?

Positiva. . . . . . . . . . . . . 1

Negativa. .............. 2

¿Por qué?

11. ¿Qué opinión tiene sobre el modelo de incubación de BA?

Positiva. . . . . . . . . . . . . 1

Negativa. . . . . . . . . . . . 2

¿Por qué?

12. Como emprendedor ¿qué mejoras propondría con relación a los productos y servicios de apoyo ofrecidos por BA? 
13. ¿Cuál es su opinión y valoración sobre el papel de BA en el acceso a los siguientes recursos y capacidades?

- Recursos humanos (personal, formación técnica y conocimiento del sector)

- Recursos sociales (acceso a redes)

- Recursos financieros (capital semilla, acceso a financiación, reducción del riesgo de potenciales inversores).

- Recursos físicos (espacios a bajo coste, acceso a laboratorios, administración)

- Recursos tecnológicos (redes de investigadores y proyectos de investigación, bases de datos)

- Capacidades organizativas (asistencia legal, asesoría en el PE, "mentoring", "coaching")

\section{SECCIÓN III: Factores externos}

d) Importancia y valoración general de los factores externos que influyen en BA

14. ¿Qué opinión le merece la puesta en marca de medida de asistencia y apoyo a la creación de empresas durante los últimos años en Barcelona?

15. De las anteriores medidas de apoyo, ¿̇cuáles considera que han incidido en BA?

16. ¿Qué cambios significativos ha notado en Barcelona y Barcelona Activa, en términos de creación de empresas y desarrollo empresarial? 
